\section{Military Technical College Kobry El-Kobbah, Cairo, Egypt}

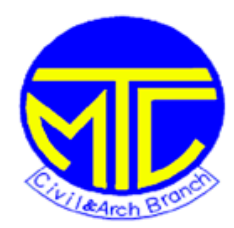

$11^{\text {th }}$ International Conference on Civil and Architecture Engineering ICCAE-11-2016

\title{
Sustainable wastewater reuse using soil aquifer treatment
}

\author{
Mahmoud A Elsheikh*, Mohamed E Basiouny**, Mohamed R Ghazy**, Rania \\ M Ibrahim** \\ * Civil Engineering Department, Faculty of Engineering, Menoufia University, Egypt \\ ** Civil Engineering Departments, Benha Faculty of Engineering, Benha University, Egypt
}

\begin{abstract}
Soil Aquifer Treatment (SAT) systems can be used for upgrading partially treated wastewater by infiltrate into the soil for tertiary treatment for reuse. In this study, a pilot plant of three columns of $2 \mathrm{~m}$ height and $25 \mathrm{~cm}$ diameter were designed and fabricated to study the quality improvement of the conventional effluent treated wastewater using three types of soil. The pilot was operated under three operational phases; first worked as 4 days wetting followed by 3 days drying cycle, the second worked as 3 days wetting followed by 4 days drying and the third phase worked as 5 days wetting and 2 days drying. The pilot plant of columns was fed using the effluent of Qaha secondary wastewater treatment plant. The results indicated that, the medium sandy soil operating with 3 days wetting/4 days drying cycles had the highest removal performance for BOD, COD and TSS (64\%, $38 \%$ and $86 \%$ ) respectively
\end{abstract}

Keywords: Soil Aquifer Treatment (SAT); Soil aquifer, Tertiary Treatment, Sewage Treatment.

\section{Introduction}

Egypt is suffering from a shortage in available water resources due to population increase and water requirement. The Egyptian ministry of water resources and irrigation has recently developed a new water policy to enhance water availability, including safe recycling of wastewater and desalination of brackish and seawater. Wastewater reuse can be achieved through a variety of methods which can globally be grouped into two main groups, direct and indirect. Each method has its advantages and disadvantages, which are very much a function of the location of treatment plants, demand for the effluent in space and time, the quality of the effluent, the characteristics of the soils and the aquifer characteristics. In general terms, the rate of effluent discharge from treatment plants is constant over the year, while demand on water, especially for agriculture, varies greatly over the year and even over the day. Moreover, direct reuse may be faced by objections from the local users knowing its origin. These factors are the essential differences between direct and indirect reuse (Elsheik, and Elhamidy 2012).

The artificial recharge using waters of impaired quality is one of many strategies that can be used, alone or in conjunction with other strategies, to augment water supplies, such as reducing water consumption or creating secondary water systems that deliver certain wastewaters directly to non- potable uses (e.g., the use of gray water for landscape irrigation). Aquifer recharge for the wastewater reuse has been considered and studied as a promising process to cope with the worldwide water scarcity (Elsheik, and Elhamidy 2015, Miller 2006, Cha et al. 2006). 
Soil aquifer treatment (SAT) has been found to be a low cost sustainable tertiary wastewater treatment technology, which has the ability to generate high quality effluent from secondary treated wastewater for potable and non-potable uses (Elsheik, and Elhamidy 2015, Essandoh, et al. 2011). Mixing of the infiltrated wastewater with the groundwater and the slow movement through the aquifer increases the contact time with the aquifer material leading to further purification of the water (Akber et al. 2003, Madhavi et al 2012).

All subsequent paragraphs are indented and justified. The maximum length for an outline paper is two A4 pages of text and references (totalling approximately 1000 words) plus two additional A4 pages for figures, tables. Outline papers must therefore not exceed four A4 pages including all references and any supporting diagrams or illustrations.

Your Introduction section should clearly set out the background and the objectives of your work. An extensive literature review is not needed for an outline paper, but you should cite those key works in the literature that had a major influence on your work. Your outline paper should then, as described below, include brief summaries of the materials/methods you used, the results you found, and the conclusions you reached.

\section{Material and Methods}

The experiments were performed using a pilot plant consisting of three parallel columns reactors, each column was constructed from a plastic tube with $2 \mathrm{~m}$ height (inner diameter of $25 \mathrm{~cm}$ and wall thickness of $0.5 \mathrm{~cm}$ ) filled by $1.5 \mathrm{~m}$ soil. Column was equipped with 8 ports at equal heights $(25 \mathrm{~cm}), 1$ constant head overflow weir were located at depths of $25 \mathrm{~cm}$ from the top of the columns and used to maintain the desired constant head at the top of the soil, and 1 column outlet at the bottom. Sampling ports were installed at depths of 50, 100 and $150 \mathrm{~cm}$ from the top of the soil and used for the collection of water samples, About $20 \mathrm{~cm}$ of headspace above the top soil was provided to pond the wastewater effluent during the flooding. Gravel support is at the bottom of the column of $10 \mathrm{~cm}$ depth as shown in "Figure 1". Each column was filled with a kind of sand soil (coarse, medium, fine). Table 1 summarizes the characteristics of the columns soil. The columns were used to simulate a SAT system by employing three phases of cyclic operations.

Table 1 Characteristics of the column soils.

\begin{tabular}{|c|c|c|c|}
\hline Variables & Column A & Column B & $\begin{array}{c}\text { Column } \\
\text { C }\end{array}$ \\
\hline Soil classification & Coarse Sand & Medium Sand & Fine Sand \\
\hline Dry bulk density $\left(\mathrm{g} / \mathrm{cm}^{3}\right)$ & 1.54 & 1.56 & 1.53 \\
\hline Effective Size $(\mathrm{mm})$ & 0.425 & 0.3 & 0.25 \\
\hline Coefficient of Uniformity & 3.6 & 2.5 & 6 \\
\hline
\end{tabular}




\section{Results and Conclusions}

This section should summarise clearly the experimental results obtained or the major outcomes of the performed study. Any trends or points of interest should be highlighted and their significance explained.

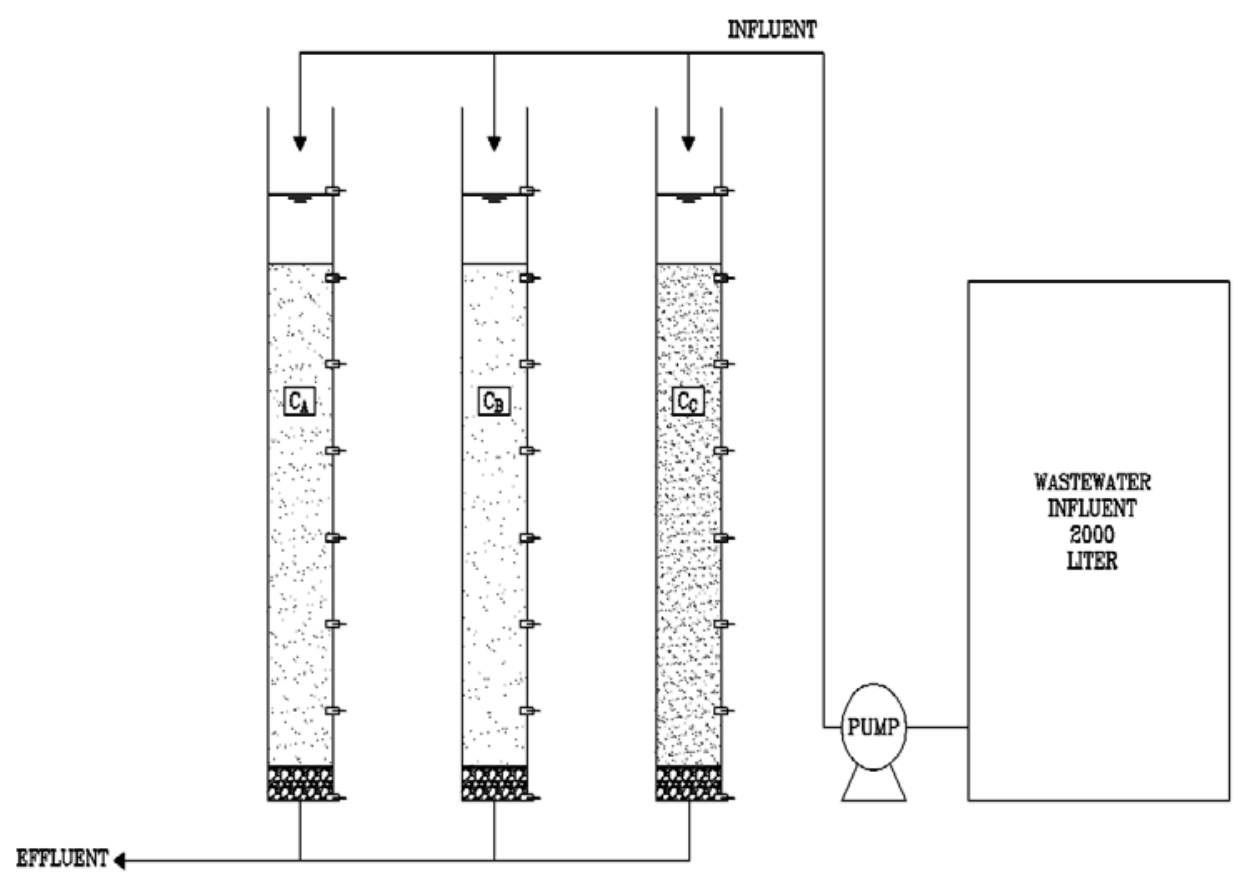

Figure 1 A schematic diagram of the SAT pilot plant system set-up used in this study.

\section{Results and Discussion}

\section{BOD and COD Removal}

Wastewater contains a variety of natural and synthetic organic compounds, usually not individually identified, but collectively expressed in terms of the $\mathrm{BOD}_{5}$, and COD. The soil with its biomass is extremely versatile and effective in decomposing natural and synthetic organic compounds that enter the soil with the wastewater. This decomposition tends to proceed more rapidly and completely under aerobic than anaerobic conditions. The fate of organic compounds in soil is normally not evaluated for each compound, but for the organic compounds collectively, as expressed by BOD5 and COD.

Figure 2 shows the average BOD removal through the fine, medium and coarse sandy soil at different operation. The influent BOD ranged between 42 and $10 \mathrm{mg} / \mathrm{L}$ and. The influent wastewater quality refers to quality of Qaha wastewater plant. The result indicated that, the medium sandy soil is the most affected soil with maximum removal efficiency $(\mathrm{Re} \%=64 \%)$ is obtained at Phase II operation cycle (3 days wetting / 4 days drying) at a flow rate $0.158 \mathrm{~L} / \mathrm{min}$.

The study of A. Akber, et al. (2003) indicates that the BOD removal efficiency was 90\% when using Muddy Sand and Gravelly Muddy sand. Madhavi, et al. (2012) find 
that the clay is suitable for removing BOD \& COD under frequent wetting and drying cycles.

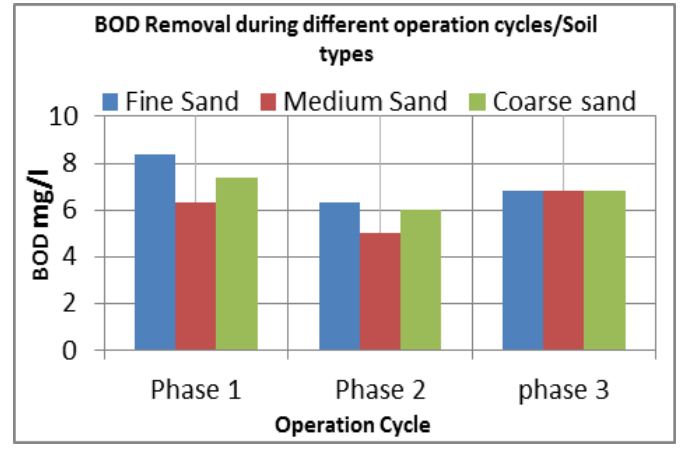

Figure 2 BOD Removal during different operation cycles/Soil types.

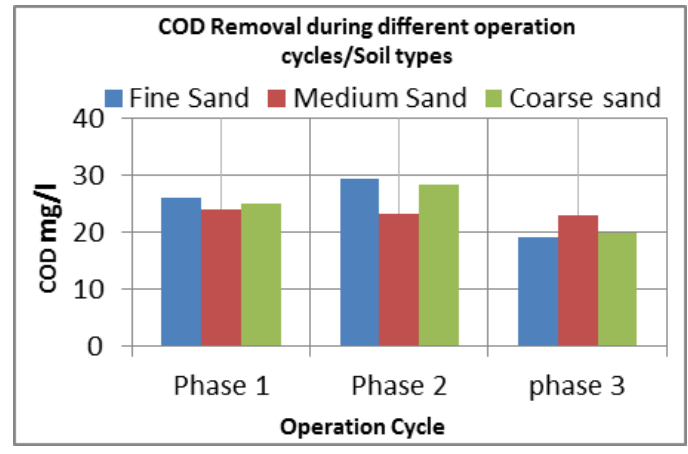

Figure 3 COD Removal during different operation cycles/Soil types.

Figures 3 shows COD removal during different operation cycles. The influent COD varied between 77 and $22 \mathrm{mg} / \mathrm{l}$, whereas the average value effluent varied between 29 and $19 \mathrm{mg} / \mathrm{l}$, for all types of soils , COD removal is not as good as BOD. This might be due to the presence of refractory organics in wastewater. Medium sand soil is considered the most affected soil for removing COD in the phase 2 by efficiency $38 \%$.

The study of A. Akber, et al. 2006 (6) indicates that the COD removal efficiency was 99\% when using Muddy Sand and Gravelly Muddy sand.

During SAT, the saturated (wet cycle) and unsaturated (dry cycle) zones of the natural soil and groundwater aquifer act as the medium in which physicochemical and biological reactions occur (Cha et al. 2006). These reactions substantially reduce the levels of organic and inorganic compounds leading to an improvement in water quality (Fox and Makam, 2009). Mixing of the infiltrated wastewater with the groundwater and the slow movement through the aquifer increases the contact time with the aquifer material leading to further purification of the water (Asano and Cotruvo. 2004; Dillon et al. 2006). Redox conditions and residence time can have a significant influence on the kinetics of dissolved organic carbon (DOC) degradation and may affect its removal efficiency (Grunheid et al. 2005).

\section{TSS Removal}

Total suspended solids (TSS) are usually rather fine and mainly in organic form (sewage sludge, bacteria, fibrous materials, algae cells, etc.). The soil, however, is a very effective filter, and suspended solids should be essentially completely removed from the wastewater after about $1 \mathrm{~m}$ of percolation (Al-Senafy et al. 2005). The TSS at the inlet varied between 43 and $8 \mathrm{mg} / \mathrm{l}$. After the application of SAT, the TSS dropped to $1 \mathrm{mg} / \mathrm{l}$ in the three phases. The highest Re\% of TSS was obtained in the case of the medium sandy soil with value $86 \%$ at phase 2 operation cycle figure 5 . Reductions of microbial in infiltrate wastewater were demonstrated using survival experiments. The reductions in microbial pathogens were attributed to a combination of physical removal processes and the activity of indigenous microorganisms (Toze and Bekele 2009). 


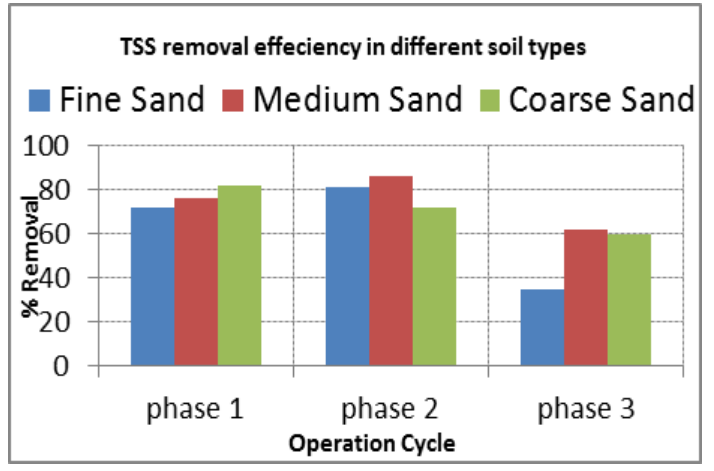

Figure 5 TSS removal efficiency in different soil types

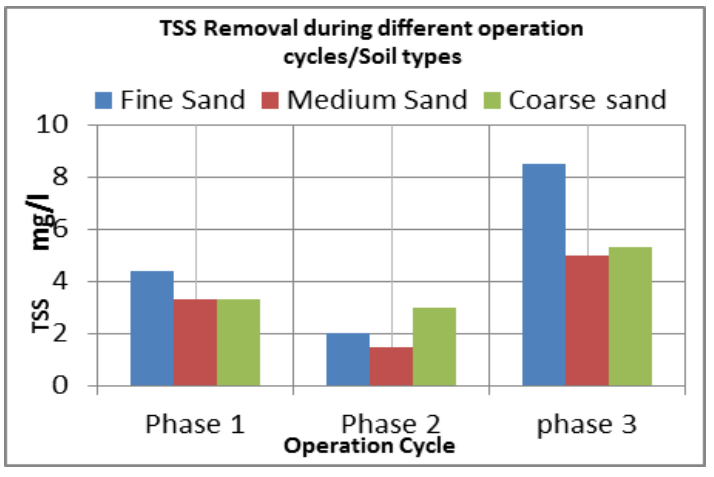

Figure 4 TSS Removal during different operation cycles/Soil types

A major operational feature of infiltration systems for treated wastewater is soil clogging caused by accumulation of suspended solids and strained out on the soil surface. The suspended solids can be inorganic, organic or grown biofilms. Their thickness may range from $1 \mathrm{~mm}$ or less to $0.3 \mathrm{~m}$ or more (Bouwer 2002). On the other hand, the controlled soil clogging accompanied with bioprocesses improves water quality. Considering both positive and negative influence of pollutant removal, biological clogging in porous media must be depicted by examining a correlation between bacterial growth and hydraulic conductivity (Page et al. 2011).

Three different clogging mechanisms were suggested depending on the flow rate and substrate concentration: (1) clogging at a high flow rate can be accelerated and easily eliminated by high shear force, (2) clogging at a low flow rate of local biofilm growths can be sloughed, and (3) clogging in a solution with high substrate concentrations cannot be easily eliminated because of the growth of dense biofilms (Kim et al. 2010).

\section{Ammonia \& Nitrate Removal}

The nitrogen removal processes in a biological filter mainly involves several ecological processes, including ammonification, aerobic ammonium oxidation, nitrite oxidation, anaerobic denitrification, heterotrophic nitrification, aerobic denitrification, anaerobic ammonium oxidation, biological nitrogen fixation, dissimulator nitrate reduction, and Achaea ammonium oxidation (Ji et al. 2013; Satoh and Rulin 2004). According to previous research, nitrification and denitrification are the main mechanisms that are responsible for eliminating nitrogen from sewage water (Dong and Sun 2007; Wang et al. 2010). Kopchynski et al. (1996) studied the effects of soil type and effluent pretreatment on soil aquifer treatment. In this study, ten $2.6 \mathrm{~m}$ columns were operated under different flooding and drying cycles. The results indicate that effluent pre-treatment has a complete removal of ammonia. 


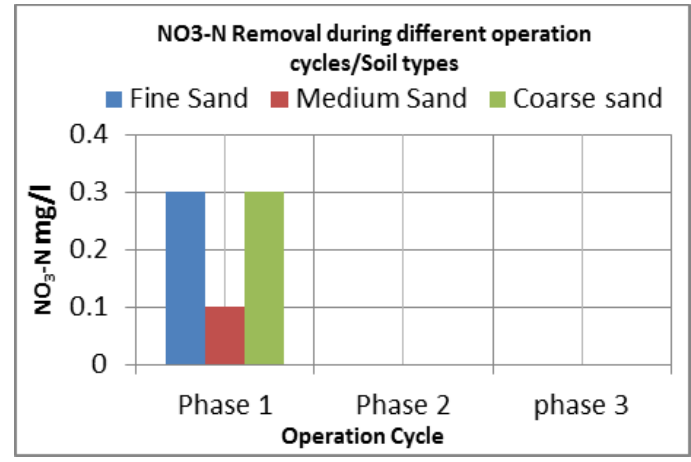

Figure 6 Nitrate Removal during different operation cycles/Soil types

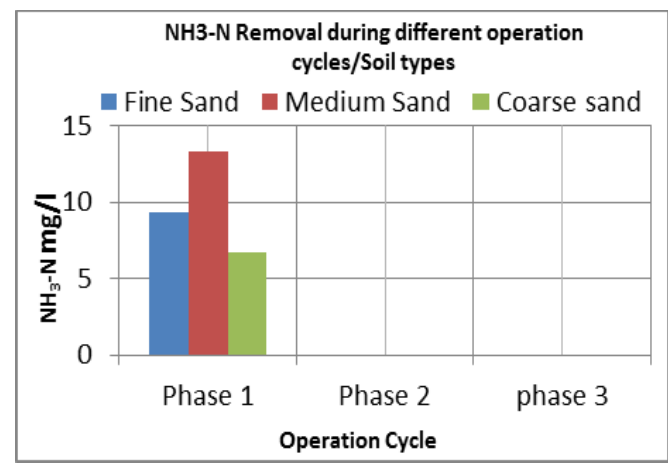

Figure 7 Ammonia Removal during different operation cycles/Soil types

In this experiment, For the first phase, the behavior of nitrate NO3-N and Ammonia NH3-N are decreasing according to the stability of SAT system. Figure 6 shows the removal in Nitrate through soil column, its value varied between 4.9 and $0.1 \mathrm{mg} / \mathrm{l}$ in the inlet for phase $1,1.5$ and $0.4 \mathrm{mg} / \mathrm{l}$ for phase 2 and varied between 1.6 to $0.2 \mathrm{mg} / \mathrm{l}$ for phase 3 . The effluent of Nitrate decreased to zero value in all soil columns at $1.5 \mathrm{~m}$ soil depth.

Figure 7 shows the removal of ammonia through fine, medium and coarse sand soil. The level of ammonia in the inlet varied between 27.2 and $1.1 \mathrm{mg} / \mathrm{l}$ for phase $1,25.7$ and $13.5 \mathrm{mg} / \mathrm{l}$ for phase 2 and varied between 18.2 to $12.3 \mathrm{mg} / \mathrm{l}$ for phase 3 . The effluent ammonia decreased to zero value in all soil columns, indicating complete conversion of ammonia to nitrate. This indicates a high aerobic environment within the subsurface zone.

Highest Re\% of ammonia and nitrate were obtained at Phase 2 operation cycle (3 days wetting / 4 days drying) for all types of soil with value $100 \%$.

The unsaturated zone (during dry cycle) has available oxygen due to ability of air flow in its porous during the drying period of the SAT treatment cycle. Availability of oxygen in the unsaturated zone is highly important in promoting aerobic biodegradation processes and nitrification. Factors influencing the efficiency of SAT include characteristics of treatment site, soil and wastewater characteristics, climate and infiltration rate (Tanik and Comakoglu 1996).

\section{Phosphate Removal}

The phosphate concentration within the effluent from Qaha WWTP was $1.1 \mathrm{mg} / \mathrm{l}$ on average. It decreased in all soils at three phases till zero value. Its known that phosphate is removed either through its adsorption by phosphate-fixing materials, such as iron oxide and aluminium oxide, or through a precipitating reaction with the calcium and magnesium ions presented in soil (Bouwer 2002). Therefore, the phosphate removal in this study indicates that the phosphate removal is depending on characteristics of the soil column. 


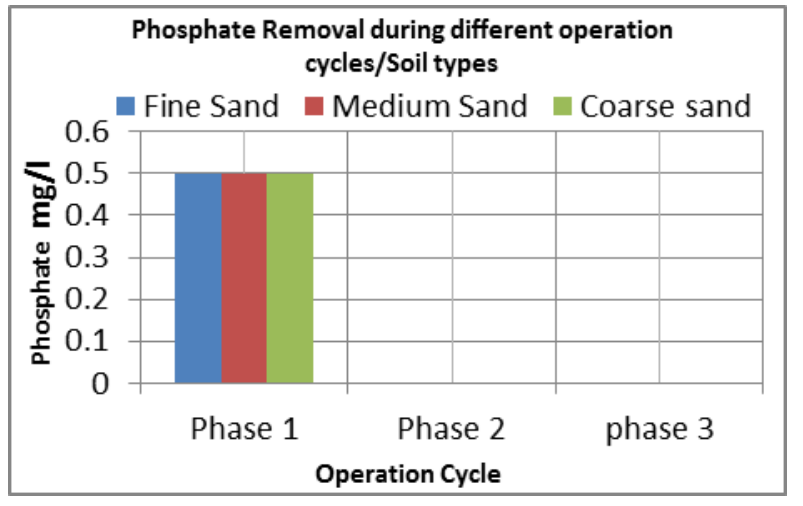

Figure 8 Phosphate Removal during different operation cycles/Soil types

Adsorption and precipitation are reported to be the main causes of phosphorous retention in calcareous sands and soils (Wandruszka 2006).

\section{Conclusions}

Soil column studies were carried out to evaluate the potential of SAT system in treating wastewater under varied experimental conditions viz. soil type, depth of soil, initial concentration of pollutants and $\mathrm{pH}$. Based on the analysis of results the following conclusions have been drawn.

- The best removal efficiency occurs at the end of soil column (1.5 m), its efficiency can be increase by increasing soil depth, but the flow rate may be decrease.

- SAT system with medium sandy soil was more efficient in treating wastewater compared to fine and coarse sand.

- Medium sand is the better soil for reducing BOD, COD and TSS under phase II operation cycle (3wetting / 4drying).

- Soil column experiments showed that nitrification can remove up to $90 \%$ of ammonium nitrogen within a soil column of $1.5 \mathrm{~m}$ depth and also denitrification can be achieved during soil passage.

- Phosphate removal was generally very high.

\section{Acknowledgement}

Special grateful appreciation is expressed to Egyptian Academy of Scientific Research and Technology for funding this work. I would like to thank the staff of water pollution control, National Research Center, and the staff of Qaha WWTP plant for their help, guidance and providing the necessary laboratory results.

\section{References}

Akber, A.; E.Al-Awadi and T.Rashid , 2003 "Assessment of the use of soil aquifer treatment technology in improving the quality of tertiary treated wastewater in Kuwait”, Emirates J. for Eng. Research, 8(2), 25-31.

Al-Senafy, M., M. Viswanathan, T. Rashid and K. Al-Fahad, 2005 "Efficiency of the SAT Technique in Improving the Quality of the Wastewater,” in Emirates J of Eng. Reasraech, 10 (1), 79-88, May 2005.

Asano, T.; J. A Cotruvo. 2004. Groundwater recharge with reclaimed municipal wastewater: health and regulatory considerations. Water Research, Volume 38, Issue 8, April 2004, 1941-1951

Bouwer, H. 2002. Artificial recharge of groundwater: hydrogeology and engineering. Hydrogeology J. 10 (1), 121-142.

Cha, W.; Kim, J., Choi, H., 2006. Evaluation of steel slag for organic and inorganic removals in soil aquifer treatment. Water Research 40 (5), 1034-1042. 
Dillon, P.; Pavelic, P., Toze, S., Rinck-Pfeiffer, S., Martin, R., Knapton, A., Pidsley, D., 2006. Role of aquifer storage in water reuse. Desalination 188 (1-3), 123-134.

Dong, Z.Q., Sun, T.H. , 2007 “A potential new process for improving nitrogen removal in constructed wetlands-promoting coexistence of partial-nitrification and ANAMMOX”. Ecol. Eng. 31, 69-78.

Elsheik, M A \& W K Elhamidy. 2012. Wastewater Reuse through Soil Aquifer Treatment. International Conference on Environment (ICENV 2012), 11-13 Dec. 2012, Penang, Malaysia.

Elsheik, M A \& W K Elhamidy. 2015. Pollution Control of Wastewater in Recharge Aquifer. International Journal of Environmental Engineering- IJEE, Volume 2 : Issue 1 [ISSN : 2374-1724]

Essandoh, H. M. K.; C. Tizaoui, M.H.A. Mohamed, G. Amy, D. Brdjanovic. 2011. Soil aquifer treatment of artificial wastewater under saturated conditions. Water Research 45 (2011) 4211- 4226.

Fox, P.\& R. Makam, 2009. Surface area and travel time relationships in aquifer treatment systems. Water Environment Research 81 (11), 2337-2343.

Grunheid, S.; Amy, G., Jekel, M., 2005. Removal of bulk dissolved organic carbon (DOC) and trace organic compounds by bank filtration and artificial recharge. Water Research 39 (14), 3219-3228.

Ji, G.D., He, C.G., Tan, Y.F. 2013. “The spatial distribution of nitrogen removal functional genes in multimedia biofilters for sewage treatment.” Ecol. Eng. 55, 35-42, 2013.

Kim J. W.; H. Choi, Y. A. Pachepsky. 2010. Biofilm morphology as related to the porous media clogging. Water Research 44 (2010) 1193-1201.

Kopchynski, T. Fox, P.Alsamadi, B. and Berner, M., 1996 “The Effects of Soil type and effluent pretreatment on soil aquifer treatment,” Water Reasearch technology 34(11). 235-242.

Madhavi, G, V.R Raji and S. Lavanya, 2012. “Aquifer Recharge with reclaimed water through soil aquifer treatment, India water week 2012- water, energy and food security, 10-14.

Miller, G. W. 2006. Integrated concepts in water reuse: managing global water needs. Desalination 187, 65-75.

Page, D.; K. Miotli-nski, P. Dillon, et al. 2011. Water quality requirements for sustaining aquifer storage and recovery operations in a low permeability fractured rock aquifer. J. of Environ. Manage. 92 (2011) 2410-2418.

Satoh, H., Rulin, B. , 2004 "Macroscale and microscale analyses of nitrification and denitrification in biofilms attached on membrane aerated biofilm reactors.” Water 483 Res. 38, 1633-1641.

Tanik, A.; Comakoglu, B., 1996. Nutrient removal from domestic wastewater by rapid infiltration system. J. of Arid Environ. 34 (3), 379-390.

Toze, S.; Bekele, E., 2009. Determining Requirements for Managed Aquifer Recharge in Western Australia. A Report to the Water Foundation. CSIRO, Canberra, AU. 2009.

Wandruszka, R. von 2006. Phosphorus retention in calcareous soils and the effect of organic matter on its mobility. Geochemical Transactions 7 (6). doi:10.1186/1467-4866-7-6.

Wang, X., Sun, T., Li, H., Li, Y., Pan, J. , 2010 "Nitrogen removal enhanced by shunt distributing wastewater in a subsurface wastewater infiltration system. ” Ecol. Eng. 36, 1433-1438. 